\title{
Appliance of Value Engineering on the Improvement of Headstock Gear
}

\author{
Zhang-wei Li \\ College of Economic Administration, Sichuan Agricultural University \\ Ya'an, 625014, China \\ E-mail: mrlizhangwei@hotmail.com \\ Xun-gang Zheng (Corresponding author) \\ College of Economic Administration, Sichuan Agricultural University \\ Ya'an, 625014, China \\ E-mail: zxg9@163.com
}

The article is supported by the Ministry of Science and Technology of the People's Republic of China. No. 2006BAJ05A13

\begin{abstract}
Based on the value engineering analysis, this article calculates the value coefficient of the headstock gear by defining the cost coefficient and functional coefficient, whose result shows that the lower cover and screw stem are the main objects to be improved, therefore, puts forward proposals to the improvement of lower cover and screw stem and finally evaluates the improving program whose result suggests improving program has a good effect.
\end{abstract}

Keywords: Value engineering, Headstock gear, Product improvement

\section{Introduction}

The ultimate goal of the enterprise is to continue business operations and gain profit, on the one hand, manufacturing technique of the society is continuously updated, only reach social necessary labor time, can the enterprise gain average profit of the industry and continue business operations, on the other hand, in order to stand out from the fierce market economy, enterprise must reduce costs and raise efficiency to gain excess profit. In addition, reduction of consumption caused by global financial crisis and the rise of the raw material prices make enterprises of China, especially small and medium-sized enterprise face greater difficulties which ask for the improvement of the products and reduction of the costs. Howerer, in China, many enterprises did not do the scientific analysis for their products, which not only made the improved results poor, but also resulted in a waste of resources.

The main purpose of this article is to find out the improved order of the headstock gear through calculating the functional coefficient, cost coefficient and vale coefficient using Value Engineering method, then put forward proposals to the improvement of lower cover and screw stem, and finally evaluates the improving program.

Lawrence D. Miles estabilished the Value Engineering in the monograph of "Techniques of Value Analysis and Engineering" in 1947. In the monograph he pointed out that success of a free enterprise in the overall long-term competition lay in continuously selling the best value to customers and evoking expected price, and the best value is function and cost. Using Value Engineering can help all the departments of a enterprise to determine the best scheme that meets all the needs of the customers with the lowest cost. In general, $15 \%$ to $20 \%$ or more of the unnecessary costs can be reduced within reducing the value of consumers. Since 1978, the theroy of Value Engineering was introduced into China, it has been widely adopted by many companies and made great economic benefits.

With 30 years' practice, the theory and methodology of Value Engineering has been recognized by the academic community, especially the business circles, which has been one of the significant methods to improve product quality, reduce product cost and increase economic efficiency.

Research on the influence of technical innovation on business management: LIU Lie-wei(2010) pointed out that the minor enterprises in China have low level of technology and innovation ability, they should set up a corporate culture of innovation core value and mechanism of innovation incentive. XU Wen-sheng(1999) pointed out that the influence of technological innovation to business management mainly lies on manufacturing activities and the main purpose is to reduce the cost, improve the yield and quality, supply material base for enterprises to maintain and enhance competitive strength. 
Meanwhile, many scholars in China have done lots of fruitful work to the application of improving product using scientific theories and methods of Value Engineering.

(1) Research on the basic analysis steps of Value Engineering: Zhou Shu-ling (2008) showed that there are 5 steps in Value Engineering Analysis to choose the best scheme as the successful bidder. The steps are determining the object of Value Engineering and doing functional analysis, calculating the functional coefficient, calculating the cost coefficient, calculating the value coefficient and evaluating the scheme, and ordering the value of the scheme. And in the step of determing the object of Value Engineering, we can use FD method, Multi-scale score method, DARE method, Logical flow score method, and AHP method.

(2) Research on the effects of Value Engineering: Ren Jie, Zhang Xiao-hua (2008) showed that Value Engineering can increase economic efficiency value, help to improve enterprise management level, promote combination of technical and economic, soft technology and hard technology.

The researches of the headstock gear have also been done by many scholars, which mainly place extra emphasis on the disadvantage and the improvement of the headstock gear.

(1) Research on the disadvantage of the headstock gear: Li Zhi-rong, Xue Song et al. (2009) showed that the disadvantages of the headstock gear are that screw is easy to bend and fractured, bushing is easy to fret, screw glissades automatically.

(2) Research on the improvement of the headstock gear: Yang Lin, Ren Shang-hua (2009) showed that we can add a screw set in the screw cover to prevent it from bending and set anti-theft feature, meanwhile the body of the headstock gear can be made of the steel to prevent the disadvantage of rust-eaten. The price of headstock gear improved can be reduced by $25 \%$ to 320 yuan per contignation. Yang Dao-fu (2008) showed that we can add a special draw-in gear in the operating arm to set the anti-theft feature. The fundamentals of the anti-theft feature are to ensure screw stem is closed and not exposed in the process of opening and closing the water gate when using special tools.

To sum up, scholars in and out of the country all agree on the point that Value Engineering is a directive significance way to the improvement of the products' cost and function, and there are some disadvantages of the headstock gear. Though there are researches on the improvement of the headstock gear, they put emphasis on the producing technology and have not do a comprehensive analysis on the value, cost and function. This article solves the disadvantage above based on the theory of Value Engineering and has strong practical significance.

\section{Theory of Value Engineering}

Value Engineering is a technical and economic method which studies on how to achive the necessary function with the lowest cost. The main idea of Value Engineering is to enhance the value of the object through analyzing the function and the cost of the object, the core is to analyze the function.

The formula of calculating the value is $V=\frac{F}{C}$

$\mathrm{V}$ stands for value coefficient, $\mathrm{F}$ stands for functional coefficient, and $\mathrm{C}$ stands for cost coefficient.

In principle, we study on the object whose $\mathrm{V}>1$ or $\mathrm{V}<1$. If $\mathrm{V}=1$, that suggests the real cost matches the function, it is a perfect situation. If $\mathrm{V}>1$, that suggests the cost of the function is low or the function is surplus, sometimes it is caused by the high cost of other components. If $\mathrm{V}<1$, that suggests the cost is on the high side or the function is insufficient. If $\mathrm{V}=0$, that suggests the component can be combined or omitted.

\section{Value engineering analysis of the headstock gear}

\subsection{Distribution of cost}

The headstock gear consists of one screw stem, lower cover, operation board, upper cover, nut and two operating arms, whose cost is $120,110,63,25,22,18$ yuan according to priority.

Each cost of components divided by the total cost of the headstock gear can we get the proportion of total costs of each components, then cumulate the proportion of total costs of each components one by one can we get the cumulative proportion of total costs. According to process above, we can calculate the result of ABC analysis of the headstock gear, as table 1 shows.

According to the principle of classification, if cumulative proportion of total costs of the component is between $60 \%-70 \%$, the component is classifiled as the A classfication, if it is between $15 \%-20 \%$, the component is classifiled as the B classfication, and if it is near 10\%, the component is classifiled as the $\mathrm{C}$ classfication. From the result, we can see that screw stem, lower cover should be taken as A class component, operation board, upper cover should be taken as B class component, and operating arm, nut should be taken as $\mathrm{C}$ class component. 


\subsection{Analyzing of function}

The basic fuction of the headstock gear is to make the water gate up and down, and the secondary function is easy to operate, durable and with a beautiful appearance. And from the feedback of user, there is a shortcoming that screw is easy to bend and headstock gear is lacking of anti-theft feature.

Through analysis of function of each component, we define the function of screw stem is to make the water gate up and down, the function of lower cover is to fix and support the headstock gear, the function of operation board is to connect operating arm and screw stem, transmit external force, the function of upper cover is to protect the headstock gear, the function of operating arm is to imput external force, and the function of nut is to support the headstock gear, drive screw stem up and down. The function definition of headstock gear' component is shown in table 2 .

\subsection{Functional evaluation}

\subsubsection{Defining the functional coefficient}

\section{(1) Defining functional importance coefficient}

Calculating the importance coefficient using absolute evaluation method which asks 6 technicists to grade for each function. Sum up the grade of each function given by the 6 technicists, and then calculate the importance coefficient using the total grade of each function given by the 6 technicists to divide by the total grade of the headstock gear.

The grade given by technicists and the result of calculating the functional importance coefficient are just like table 3 shown. From the result, we can see that functional importance coefficient of making the water gate up and down is $36.33 \%$, functional importance coefficient of easy to operate is $25.17 \%$, functional importance coefficient of durable is $30.33 \%$, functional importance coefficient of beautiful appearance is $8.17 \%$.

(2) Calculating the functional evaluation coefficient of key components

Asks 6 technicists to grade for each function of each component, the total grade of each function is 100, which is shown in table 4 . Then calculate the functional coefficient of each component shown in table 5 by multipling functional importance coefficient which is shown in table 3 and the functional proportion coefficient which is shown in table 4. From the result we can see that functional evaluation coefficient of screw stem, lower cover, operation board, upper cover, operating arm and nut is $0.2449,0.1400,0.1974,0.0770,0.0820$ and 0.2587 .

\subsubsection{Defining the cost coefficient}

Calculating the cost coefficient of the 6 key components according to their current cost, the result is shown in table 6. From the result we can see that the cost coefficient of screw stem, lower cover, operation board, upper cover, operating arm and nut is $0.3352,0.3073,0.1760,0.0698,0.0614$ and 0.0503 .

\subsubsection{Calculating the value coefficient}

The 6 key components' value coefficient can be calculated according to functional evaluation coefficient table(table 5) and cost coefficient table(table 6), which as table 7 shown, in order to determine the target of improvement. The value coefficient of screw stem, lower cover, operation board, upper cover, operating arm and nut is $0.7306,0.4556,1.1216,1.1032,1.3355$ and 5.1431 . So the order of the components to be improved is lower cover, screw stem, upper cover, operation board, operating arm and finally the nut.

\subsubsection{Result of value analysis}

According to the value coefficient of the 6 key components shown in table 7, we can come to a conclusion:

(1) Lower cover and screw stem are the main components need to be improved, for their value coefficients are less than 1, which means the function are too less or the cost are too much.

(2) Operation board and upper cover need not to be improved for their value coefficients are close to 1 which means the function and the cost are nearly the same.

(3) The coefficients of nut and operating arm are more than 1, which means the cost is already lower compared with function that has already met the needs. And in this condition, nut and operating arm are not the target of value analysis, we may neglect the analysis of them.

\section{Conclusion and Improving Suggestion}

The analysis of value engineering suggests that we should improve the headstock gear according to the order of lower cover, screw stem, upper cover, operation board, operating arm and nut, in order to meet the need and reduce the cost. On the other hand, consumers require to the anti-theft feature, so we should take it into consideration when improving. 


\subsection{Suggestion on the improvement of lower cover}

From the definition of function, we can see that the function of lower cover is to fix and support the headstock gear. For the function of the lower cover is determined by the structure of the headstock gear and its function has already met the needs, it is not work to raise the value coefficient through promoting the function, so we can do nothing but reduce the cost of the lower cover to promote the value coefficient.

At present, gray cast-iron (HT200) is widely used as the material of lower cover, we can look for a new material which has equal or better function on intensity, hardness, cost and so on to replace the gray cast-iron.

\subsection{Suggestion on the improvement of screw stem}

From the feedback of user, there is a shortcoming that screw is easy to bend and headstock gear is lacking of anti-theft feature. So the improvement of screw stem should focus on raising its function.

(1) Screw bending solution

Add a screw set in the screw cover, so it can prevent its bending and achieve the purpose of security.

(2) Improving the function of anti-theft

Add a special draw-in gear in the operating arm, which can be used to open the head and operate the gate. It is the only way to open the screw top cover and a tool for opening and closing gates. The process of opening the gate, it can ensure that the screw is closed and unexposure at any opening degree, playing the role in anti-theft and anti-sabotage.

Meanwhile, we can also raise the value coefficient by the way of looking for new material with high performance and cheaper cost.

\subsection{Improving program evaluation}

According to the conclusion of YANG Lin and REN Shang-hua in the article of discussing on the benefit of improvement and use of new type headstock gear, the cost of improved headstock gear can be reduced to 320 yuan per contignation, therefore we fix a target cost of 320 yuan, then calculate the target reduction of each component' cost which is shown in table 8 through multipling functional evaluation coefficient and total target cost.

From the result, we can see the target cost of screw stem, lower cover, operation board, upper cover, operating arm and nut is $78.37,44.80,63.17,24.64,26.24,82.78$. Compared to the real cost, we can see that the cost of screw stem and lower cover can separately be cut down 41.63 yuan and 65.20 yuan, which can be achieved by the appliance of new material and new technology. The cost of operation board and upper cover is nearly the same before which means existing technology and improved technology are nearly the same and need not to be improved. The current cost of nut and operating arm is obviously lower than improved cost, which means existing technology is better than improved technology, also need not to be improved.

Through evaluating the improving program, we can see that the headstock gear improved based on the Value Engineering can solve the disadvantange of screw bending and lacking of anti-theft feature, with the cost can be reduced to 320 yuan per contignation.

\section{References}

Lawrence D. (1972). Miles.Techniques of Value Analysis and Engineering, New York, Mcgraw-Hill (Tx), June.

LI, Zhi-rong, XUE Song, NI Cui-ping (2009). Installation, maintenance and conservation of the headstock gear. Water Conservancy of JiangSu Province, 12:27-28

LIU Lie-wei. (2010). Strategy on choice of technological innovation and management for small and medium-sized enterprise. Knowledge Economy, 6:107

REN Jie, ZHANG, Xiao-hua. (2008). Appliance of Value Engineering on the construction enterprise. Construction Economy, 6:50-51

XU, Wen-sheng. (1999). Discussing on the influence of technical progress on the management of enterprise. Management Science of Shanghai, 6:33-34

YANG ,Dao-fu. (2008). Improvement of the headstock gear. Yellow River, 4:30-31

YANG, Lin, REN, Shang-hua. (2009). Discussing on the benefit of improvement and use of new type headstock gear. Water Conservancy of Inner Mongolia Autonomous Region, 2:58-59

ZHOU Shu-ling. (2008). To Apply on Commenting of the Value Engineering in Tendering for the Construction Projects. Value Engineering, 4:90-92 
Table 1. ABC Analysis on the Headstock gear

\begin{tabular}{llllllll}
\hline Name of Component & Number & $\begin{array}{l}\text { Proportion } \\
\text { the } \\
\text { Number }\end{array}$ & $\begin{array}{r}\text { of } \\
\text { Total }\end{array}$ & $\begin{array}{l}\text { Current } \\
\text { Cost } \\
\text { (yuan) }\end{array}$ & $\begin{array}{l}\text { Proportion of } \\
\text { Total Costs }\end{array}$ & $\begin{array}{l}\text { Cumulative } \\
\text { Proportion } \\
\text { Total Costs }\end{array}$ & of \\
\hline Screw Stem & 1 & $14.286 \%$ & 120 & $33.52 \%$ & $33.52 \%$ & A \\
Lower Cover & 1 & $14.286 \%$ & 110 & $30.73 \%$ & $64.25 \%$ & $\mathrm{~A}$ \\
Operation Board & 1 & $14.286 \%$ & 63 & $17.60 \%$ & $81.85 \%$ & $\mathrm{~B}$ \\
Upper Cover & 1 & $14.286 \%$ & 25 & $6.98 \%$ & $88.83 \%$ & $\mathrm{~B}$ \\
Operating Arm & 2 & $28.570 \%$ & 22 & $6.15 \%$ & $94.98 \%$ & $\mathrm{C}$ \\
Nut & 1 & $14.286 \%$ & 18 & $5.02 \%$ & $100.00 \%$ & $\mathrm{C}$ \\
Total & 7 & $100 \%$ & 358 & $100 \%$ & & & \\
\hline
\end{tabular}

Table 2. Function Definition of Headstock gear' Component

\begin{tabular}{ll}
\hline Name of Component & Function Definition \\
\hline Screw Stem & To Make the Water Gate Up and Down \\
Lower Cover & To Fix and Support the Headstock Gear \\
Operation Board & To Connect Operating Arm and Screw Stem, Transmit External Force \\
Upper Cover & To Protect the Headstock Gear \\
Operating Arm & To Imput External Force \\
Nut & To Support the Headstock Gear, Drive Screw Stem Up and Down \\
\hline
\end{tabular}

Table 3. Calculating the Functional Coefficient

\begin{tabular}{llllllllll}
\hline & \multicolumn{1}{l}{ Expert Rating } & & & & Functional \\
\cline { 2 - 6 } Function of Headstock gear & A & B & C & D & E & F & General Comments Scores & $\begin{array}{l}\text { Importance } \\
\text { Coefficient }\end{array}$ \\
\hline Make the Water Gate Up and Down & 30 & 40 & 35 & 36 & 39 & 38 & 218 & $36.33 \%$ \\
Easy to Operate & 25 & 23 & 25 & 28 & 26 & 24 & 151 & $25.17 \%$ \\
Durable & 30 & 27 & 36 & 29 & 32 & 28 & 182 & $30.33 \%$ \\
Beautiful Appearance & 15 & 10 & 4 & 7 & 3 & 10 & 49 & $8.17 \%$ \\
Total & 100 & 100 & 100 & 100 & 100 & 100 & 600 & 1.0000 \\
\hline
\end{tabular}

Table 4. Functional Distribution Table of the Key Components

\begin{tabular}{lllll}
\hline \multirow{2}{*}{ Name of Component } & Functional Item (\%) & & \\
\cline { 2 - 5 } & $\begin{array}{l}\text { Make the Water Gate Up and } \\
\text { Down }\end{array}$ & Easy to Operate & Durable & $\begin{array}{l}\text { Beautiful } \\
\text { Appearance }\end{array}$ \\
\hline Screw Stem & 30 & 25 & 20 & 15 \\
Lower Cover & 0 & 25 & 20 & 20 \\
Operation Board & 20 & 25 & 15 & 20 \\
Upper Cover & 0 & 0 & 20 & 20 \\
Operating Arm & 15 & 0 & 5 & 15 \\
Nut & 35 & 25 & 20 & 10 \\
Total & 100 & 100 & 100 & 100 \\
\hline
\end{tabular}


Table 5. Functional Evaluation Coefficient of Key Components

\begin{tabular}{|c|c|c|c|c|c|c|}
\hline \multirow[b]{2}{*}{ Name of Component } & \multicolumn{5}{|l|}{ Functional Item } & \multirow[b]{2}{*}{$\begin{array}{l}\text { Functional } \\
\text { Evaluation } \\
\text { Coefficient }\end{array}$} \\
\hline & $\begin{array}{l}\text { Make the Water Gate } \\
\text { Up and Down } 0.3633\end{array}$ & $\begin{array}{l}\text { Easy to } \\
0.2517\end{array}$ & Operate & $\begin{array}{l}\text { Durable } \\
0.3033\end{array}$ & $\begin{array}{l}\text { Beautiful } \\
\text { Appearance } \\
0.0817\end{array}$ & \\
\hline Screw Stem & 0.1090 & 0.0629 & & 0.0607 & 0.0123 & 0.2449 \\
\hline Lower Cover & & 0.0630 & & 0.0607 & 0.0163 & 0.1400 \\
\hline Operation Board & 0.0727 & 0.0629 & & 0.0455 & 0.0163 & 0.1974 \\
\hline Upper Cover & & & & 0.0607 & 0.0163 & 0.0770 \\
\hline Operating Arm & 0.0545 & & & 0.0152 & 0.0123 & 0.0820 \\
\hline Nut & 0.1271 & 0.0629 & & 0.0605 & 0.0082 & 0.2587 \\
\hline Total & & & & & & 1.0000 \\
\hline
\end{tabular}

Table 6. Cost Coefficients Table

\begin{tabular}{lll}
\hline Name of Component & $\begin{array}{c}\text { Cost } \\
(\text { yuan })\end{array}$ & Cost Coefficients \\
\hline Screw Stem & 120 & 0.3352 \\
Lower Cover & 110 & 0.3073 \\
Operation Board & 63 & 0.1760 \\
Upper Cover & 25 & 0.0698 \\
Operating Arm & 22 & 0.0614 \\
Nut & 18 & 0.0503 \\
Total & 358 & 1.0000 \\
\hline
\end{tabular}

Table 7. Value Coefficient Table

\begin{tabular}{|c|c|c|c|c|c|}
\hline Name of Component & $\begin{array}{l}\text { Functional } \\
\text { Coefficient } \\
\text { (F) }\end{array}$ & Evaluation & $\begin{array}{l}\text { Cost Coefficient } \\
\text { (C) }\end{array}$ & $\begin{array}{l}\text { Value Coefficient } \\
\text { (V) }\end{array}$ & $\begin{array}{l}\text { Order } \\
\text { Improvement }\end{array}$ \\
\hline Screw Stem & 0.2449 & & 0.3352 & 0.7306 & (2) \\
\hline Lower Cover & 0.1400 & & 0.3073 & 0.4556 & (1) \\
\hline Operation Board & 0.1974 & & 0.1760 & 1.1216 & (4) \\
\hline Upper Cover & 0.0770 & & 0.0698 & 1.1032 & (3) \\
\hline Operating Arm & 0.0820 & & 0.0614 & 1.3355 & (5) \\
\hline Nut & 0.2587 & & 0.0503 & 5.1431 & (6) \\
\hline
\end{tabular}

Table 8. Target Cost of Component Table

\begin{tabular}{lllllll}
\hline Name of Component & $\begin{array}{l}\text { Functional } \\
\text { Evaluation } \\
\text { Coefficient }\end{array}$ & $\begin{array}{l}\text { Componets } \\
\text { Cost }\end{array}$ & $\begin{array}{l}\text { Cost } \\
\text { Coefficient }\end{array}$ & $\begin{array}{l}\text { Value } \\
\text { Coefficient }\end{array}$ & $\begin{array}{l}\text { Target } \\
\text { Cost }\end{array}$ & $\begin{array}{l}\text { Amount of } \\
\text { Reduction }\end{array}$ \\
\hline Screw Stem & 0.2449 & 120 & 0.3352 & 0.7306 & 78.37 & +41.63 \\
Lower Cover & 0.1400 & 110 & 0.3073 & 0.4556 & 44.80 & +65.20 \\
Operation Board & 0.1974 & 63 & 0.1760 & 1.1216 & 63.17 & -0.17 \\
Upper Cover & 0.0770 & 25 & 0.0698 & 1.1032 & 24.64 & +0.36 \\
Operating Arm & 0.0820 & 22 & 0.0614 & 1.3355 & 26.24 & -4.24 \\
Nut & 0.2587 & 18 & 0.0503 & 5.1431 & 82.78 & -64.78 \\
Total & 1.0000 & 358 & 1.0000 & & 320 & 38 \\
\hline
\end{tabular}

